\title{
Editorial: Presente e futuro do controle por pares e da editoração científica no Direito - perspectivas a partir dos dados da RBDPP em 2017 e das visões de seus autores e avaliadores
}

Editorial: Present and future of peer review and scientific publishing in Law - perspectives from the Brazilian Journal of Criminal Procedure data in 2017 and the views of its authors and reviewers

\section{Vinicius Gomes de Vasconcellos}

Pós-doutorando na Universidade Federal do Rio de Janeiro - Rio de Janeiro/RJ Doutor em Direito na Universidade de São Paulo - São Paulo/SP Editor-chefe da RBDPP e editor-assistente da RBCCRIM vgomesv@gmail.com

lattes.cnpq.br/9628659956663949

orcid.org/0000-0003-2020-5516

p publons.com/a/1174099/

Resumo: A partir das estatísticas e projetos implementados na RBDPP e de dados obtidos em pesquisas realizadas com autores e avaliadores da revista, este editorial pretende analisar aspectos do controle por pares e do cenário da produção científica do Direito em periódicos. Nesse sentido, as informações apresentadas reforçam a importância de um projeto editorial pautado por seriedade, publicidade e transparência, com adoção de postura ativa pelos editores, valorização dos avaliadores, além de consolidação das rodadas de correções e do dever de resposta de autores.

PALAVRAs-ChaVe: editorial; controle por pares; pesquisa com autores e avaliadores; questionário; produção científica.

AвSTRACT: Based on the statistics and projects implemented in the Brazilian Journal of Criminal Procedure and data obtained from research conducted with authors and reviewers, this editorial intends to analyze aspects of peer review and the scenario of Law scientific production in journals. In this sense, the 
information presented reinforces the importance of an editorial project based on seriousness, publicity and transparency, with the adoption of an active posture by the editors, recognition of the reviewers, as well as consolidation of corrections rounds system and the authors' duty to respond to it.

KEY-wORDS: editorial; peer review; research with authors and reviewers; questionnaire; scientific production.

No ano de 2017, a RBDPP consolidou o seu projeto editorial com a publicação de três números, cada um com dossiê temático específico junto a artigos nas seções ordinárias do periódico, em conformidade com a proposta de reformulação e os editais de chamadas públicas divulgados em 2016. Os dados e estatísticas foram:

\begin{tabular}{|c|c|c|c|c|}
\hline & V3N1 & V3N2 & V3N3 & $\begin{array}{l}\text { Total } \\
2017\end{array}$ \\
\hline ARTIGOS RECEBIDOS & 18 & 22 & 19 & 59 \\
\hline "de doutores & 5 & 10 & 7 & 22 \\
\hline “ do RS & 0 & 1 & 3 & 4 \\
\hline “ autor vínc. estrangeiro & 2 & 5 & 3 & 10 \\
\hline APROVADOS POR PARES & 11 & 8 & 8 & 27 \\
\hline CONVIDADOS & 1 & 1 & 2 & 4 \\
\hline PUBLICADOS & 12 & 9 & 10 & 31 \\
\hline$\%$ exogenia artigos & $100 \%$ & $100 \%$ & $80 \%$ & \\
\hline$\%$ artigos com doutor & $40 \%$ & $88 \%$ & $40 \%$ & \\
\hline $\begin{array}{l}\text { \% artigos com vínc. } \\
\text { estrangeiro }\end{array}$ & $25 \%$ & $33 \%$ & $30 \%$ & \\
\hline NA FILA P/ PRÓX. No & 1 & 3 & 0 & \\
\hline REJEITADOS & 7 & 12 & 8 & 27 \\
\hline “preliminarmente & 3 & 7 & 4 & 14 \\
\hline “pelos pares & 4 & 5 & 4 & 13 \\
\hline
\end{tabular}




\begin{tabular}{|c|c|c|c|c|}
\hline & V3N1 & V3N2 & V3N3 & $\begin{array}{l}\text { Total } \\
2017\end{array}$ \\
\hline Retirados pelos autores & 0 & 0 & 1 & 1 \\
\hline MÉDIA APROVAÇÃO & 0,61 & 0,36 & 0,42 & 0,45 \\
\hline PARECERES SOLICITADOS & 44 & 50 & 52 & 146 \\
\hline sem retorno & 4 & 7 & 7 & 18 \\
\hline pareceres recebidos & 37 & 41 & 39 & 117 \\
\hline$\%$ exogenia avaliadores & $94 \%$ & $97 \%$ & $96 \%$ & \\
\hline redistribuição solicitada & 3 & 2 & 6 & 11 \\
\hline MÉDIA RETORNO & 0,84 & 0,82 & 0,75 & 0,80 \\
\hline
\end{tabular}

Três dossiês foram publicados, sobre temáticas específicas, atuais e relevantes do direito processual penal sob a responsabilidade de editores-associados com produção e conhecimento nas respectivas áreas: “Colaboração Premiada e Justiça Criminal Negocial”, "Investigação Preliminar, meios ocultos e novas tecnologias" e "Oralidade e Garantias Processuais Penais”.
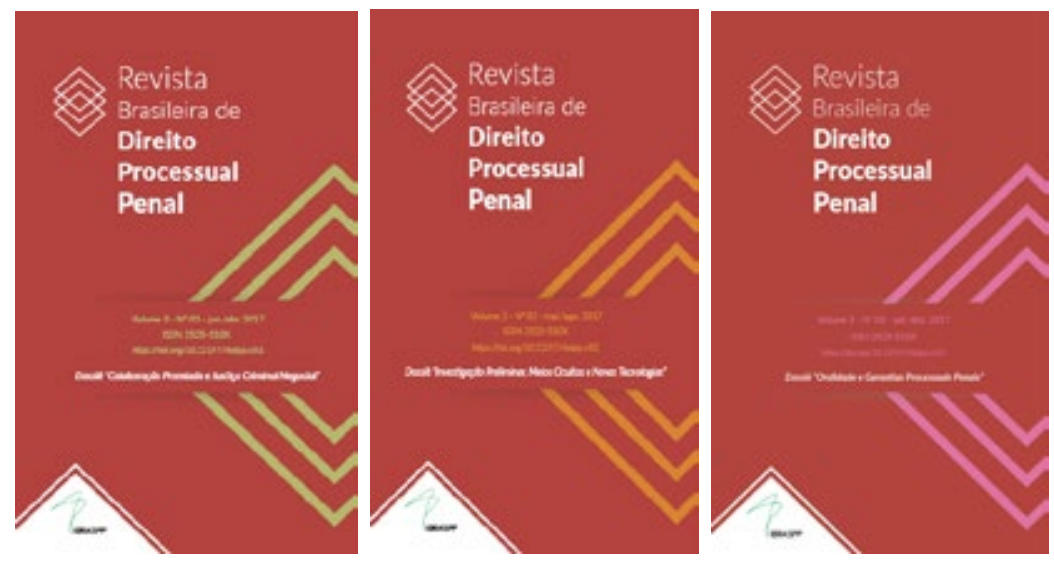

Além disso, a revista obteve certificados importantes da qualidade e da integridade do processo editorial. O ingresso em sistemas como 
DOAJ e Latindex (Catálogo) pressupõe o cumprimento de standards internacionais de editoração científica. Além disso, o cadastro de todos os artigos publicados em diretórios, bibliotecas e indexadores, como Google Scholar, Dialnet, IBCCRIM e Crossref (em razão da atribuição de DOI), possibilita a publicização da produção, ampliando, assim, o seu impacto. ${ }^{1}$

Contudo, o que parece mais relevante após o encerramento desse ano é a afirmação de um projeto editorial pautado pelas premissas de seriedade, publicidade e transparência, que paulatinamente tende a se implementar na área do Direito. ${ }^{2}$ Nesse sentido, três foram os pilares da proposta adotada: postura ativa de editores; valorização dos avaliadores; e consolidação das rodadas de correções e do dever de resposta de autores.

Durante o processo editorial, do recebimento da submissão até a publicação, o editor possui um papel fundamental na produção do conhecimento, que não pode ser somente burocrático e mecânico, mas que pressupõe atividade acadêmica consistente. ${ }^{3}$ Desde o controle preliminar, passando pela designação de avaliadores e controle dos pareceres, até a decisão editorial e o manejo das rodadas de correção, é necessário que o editor responsável tenha conhecimento científico específico sobre a temática e o método de estudo. Além disso, na RBDPP, o editor tem especial relevância ao também emitir um parecer sobre o artigo, com críticas próprias e a consolidação das avaliações anônimas, devendo, para isso, ler integralmente o trabalho em avaliação. Ao final de cada artigo

1 Em discussão sobre impacto na produção científica de processo penal, ver: CAPPARELLI, Bruna; GIACOMOLLI, Nereu J. Editorial: a avaliação do impact Factor na publicação científica de Direito Processual Penal, p. 789-806.

2 Vale ressaltar que há uma tendência de valorização da produção científica no Direito em periódicos científicos, com o objetivo de romper a "cultura de livros" anterior, exatamente em razão do maior rigor e seriedade do controle por pares de revistas científicas: “(...) a publicação em periódicos poderia levar a uma melhoria na qualidade científica do conhecimento produzido na área do Direito, uma vez que os periódicos passam por processos muito mais rigorosos de avaliação e controle de cientificidade" (SILVEIRA, Vladmir O.; SANCHES, Samyra H. F. N. Periódicos na área do Direito, p. 158). Também se remete a: GALÍCIA, Caíque R. Editorial: O pesquisador e a pesquisa em ciências criminais na contemporaneidade, p. 769-787.

3 Sobre isso, ver: VASCONCELLOS, Vinicius G. Editorial: a função do periódico científico e do editor para a produção do conhecimento no Direito e nas ciências criminais, p. 9-17. 
publicado, como medida de transparência, indica-se o/a/s editor/a/s responsáveis em "equipe envolvida".

A postura ativa de editores não esvazia, mas valoriza o controle por pares, que, em um cenário de pouco reconhecimento (pelos próprios pesquisadores e pelos órgãos de fomento, como Capes), expõe a grande dificuldade de qualquer revista científica: conseguir pareceristas pontuais, interessados e competentes. ${ }^{4}$ Para buscar melhorar tal panorama, a RBDPP, além de enviar declarações da produção, publicou pareceres de destaque como "críticas científicas", firmou parceria com o sistema Publons para certificar e reconhecer a atuação, destacou avaliadores de excelência com premiação e assegurou o feedback aos revisores, com o envio da decisão editorial sobre o artigo e os demais pareceres anônimos recebidos.

Para valorização do controle por pares e do processo editorial como um todo, medida indispensável é a consolidação da sistemática de rodada(s) de correção(ões), com a fortificação do dever de motivação aos autores na carta-resposta aos pareceres. Sem dúvidas, autores não são obrigados a atender todas as sugestões ou modificar premissas e teses sustentadas, mas devem considerar todas as críticas e responder positivamente ou negativamente, justificando eventuais recusas. Esse é um ponto de tensão em uma cultura onde a crítica científica é muitas vezes pessoalizada e que se pensa que o trabalho do pesquisador se encerra com a submissão do artigo à revista. ${ }^{5}$

Para verificar a percepção de pesquisadores envolvidos com a revista sobre tais posturas, realizou-se pesquisa voluntária, com solicitação de preenchimento de questionário com perguntas abertas e fechadas. Assim, submeteu-se um formulário a todos os autores (e coautores) de artigos aprovados e rejeitados, e outro para os avaliadores que emitiram ao menos um parecer no ano.

Com relação à pesquisa enviada aos autores, o questionário examinava a visão do pesquisador sobre o processo editorial de um modo amplo e sobre propostas futuras em relação ao controle por pares. A solicitação

4 Sobre isso: VASCONCELLOS, Vinicius G. Editorial: controle por pares e a função do revisor, p. 437-458.

5 Sobre isso: VASCONCELLOS, Vinicius G. Editorial: As rodadas de correções e a carta-resposta do autor à aprovação condicionada, p. 757-768. 
foi enviada por e-mail para 63 autores, de artigos submetidos aos números da revista de 2017, aprovados e rejeitados, incluindo todos os escritores de artigos em coautoria. Tivemos retorno de 28 respostas, ou seja, $44 \%$ dos autores, dos quais a maioria obteve um resultado positivo na submissão.

Um primeiro ponto interessante diz respeito aos principais critérios que determinam a escolha do periódico ao qual o autor submeterá o trabalho. Conforme exposto, o primordial aos pesquisadores é o estrato Qualis que se encontra a revista. Embora justificável no cenário atual de cobrança por produtividade, tal informação idealmente não deve ser tão relevante neste momento, pois a avaliação realizada pelas comissões Qualis-Capes possui características que não recomendam a sua utilização em perspectiva distinta de sua estrita finalidade: avaliar os PPGs de um modo retroativo. ${ }^{6}$ Por exemplo, o estrato Qualis divulgado em 2017 diz respeito às produções do quadriênio 2013-2016, de modo que as publicações posteriores serão submetidas a nova avaliação e serão valoradas a partir do estrato divulgado posteriormente. Portanto, é muito mais importante confiar no projeto editorial e na equipe de editores da revista (que assegurarão a continuidade da sua excelência) do que considerar cegamente o estrato Qualis atual do periódico.

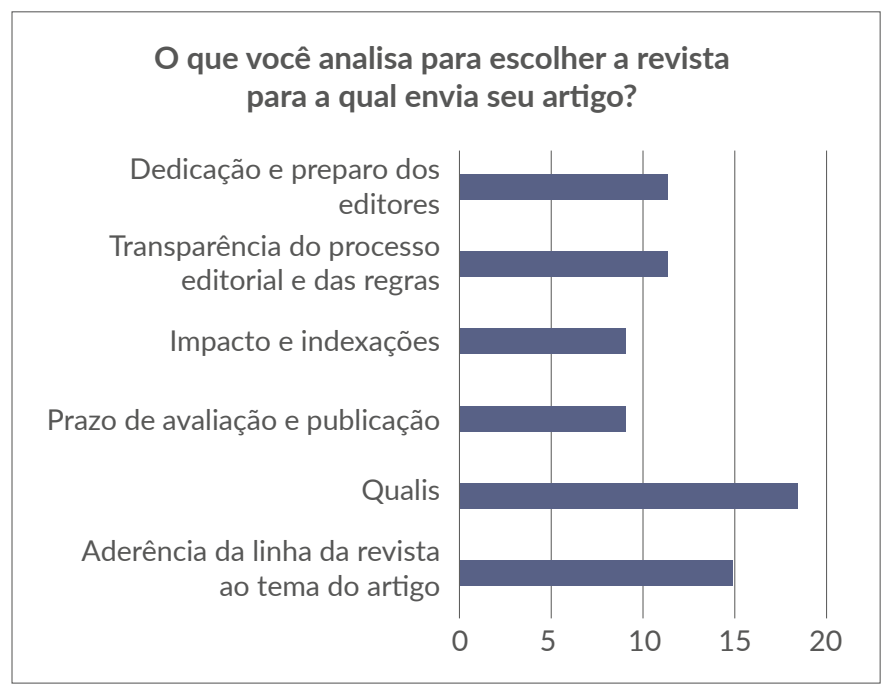

6 BARATA, Rita C. B. Dez coisas que você deveria saber sobre o Qualis, p. 17. 


\section{Você ficou satisfeito com o processo editorial de um modo geral?

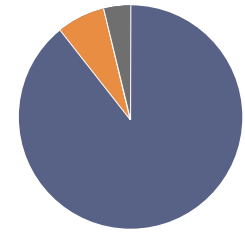 \\ Totalmente satisfeito (25) \\ Parcialmente satisfeito (2) \\ Insatisfeito (1)}

Outro dado relevante, diante das inovações do projeto editorial da RBDPP, é a satisfação dos pesquisadores. Conforme exposto acima, a quase totalidade dos pesquisadores ficou satisfeita com o processo editorial da RBDPP. Além disso, todos os 28 autores consideraram o prazo até o envio da decisão editorial razoável, entre os quais 32\% destacaram que a resposta foi "muita rápida”. Com relação aos pareceres recebidos, $75 \%$ dos autores ficaram totalmente satisfeitos, $21 \%$ parcialmente satisfeitos e $4 \%$ insatisfeitos. A partir disso, $82 \%$ afirmaram que o artigo foi aprimorado ao longo da(s) rodada(s) de correções.

Uma das principais premissas da RBDPP é a adoção de um processo editorial consistente e rigoroso, que almeja apresentar o máximo de críticas e sugestões ao autor nos pareceres enviados. Vale ressaltar que a adoção de uma postura ativa para valorização do controle por pares e das rodadas de correções não acarreta intromissão na liberdade de pensamento e expressão dos autores, pois é plenamente aceitável que ocorram eventuais recusas às críticas e sugestões, as quais devem ser justificadas. Como regra, a equipe editorial não insistirá em modificações de conteúdo, as quais almejam, na realidade, que o autor problematize e fortifique as suas próprias posições, e não altere sua visão.

Entre os pesquisadores que submeteram artigos para a RBDPP, a grande maioria (24 dos 28 autores) expressou visão positiva em relação à postura adotada pela equipe editorial no controle por pares, afirmando que "as rodadas de correções e o dever de resposta do autor a todos os pareceres" é "uma medida fundamental para o processo editorial” e "uma condição para valorização do trabalho dos 
avaliadores". 7 Sem dúvidas, a crítica respeitosa e bem fundamentada, ainda que dura, é um sinal de valorização e reconhecimento ao trabalho, pois somente é capaz de opor uma crítica consistente aquele leitor que leu e pensou com dedicação sobre a tese sustentada pelo autor.

Posteriormente, em relação à pesquisa enviada aos pareceristas, o questionário examinava a visão do pesquisador sobre o processo editorial de um modo amplo e a sua atuação como avaliador no sistema de controle por pares. A solicitação foi enviada por e-mail para 67 revisores ativos em 2017, que finalizaram ao menos um parecer referente aos números da revista no ano. Tivemos retorno de 44 respostas, ou seja, $66 \%$ dos avaliadores.

Ao todo foram emitidos 117 pareceres, uma média de 1,75 por avaliador ativo da RBDPP em 2017. Considerando que 40 artigos passaram por controle por pares, a média de pareceres por artigo foi 2,92, ou seja, como regra, quase todos os artigos foram avaliados por três revisores externos. Um primeiro dado interessante diz respeito aos motivos que levam o pesquisador a atuar como parecerista de revistas científicas: ${ }^{8}$

7 Em pesquisa realizada por meio de entrevista a 2004 avaliadores, $74 \%$ dos revisores afirmaram que o controle por pares acarreta efetivo aprimoramento aos artigos científicos e $82 \%$ concordou com a frase "sem revisão por pares não há controle sobre a comunicação científica” (WARE, Mark. Peer review survey 2015, p. 10) (tradução livre). De modo semelhante, na pesquisa de 2009: WARE, Mark. Peer review, p. 14.

8 Em pesquisas realizadas, apontou-se que os principais motivos eram: "fazer a sua parte na comunidade acadêmica", "apreciar ajudar no aprimoramento dos artigos", "gostar de ter contato com os estudos antes de sua publicação" (ou seja, conhecer o que está sendo produzido nas pesquisas de ponta antes da divulgação ampla) e "retribuir as avaliações feitas por outros pareceristas aos próprios trabalhos" (WARE, Mark. Peer review, p. 8) (tradução livre). Assim também em pesquisa mais recente: WARE, Mark. Peer review survey 2015, p. 36. Em estudo com avaliadores brasileiros: SHIGAKI, Helena; PATRUS, Roberto. Revisão por pares e produtivismo acadêmico sob a ótica de avaliadores de artigos de periódicos em Administração, p. 410-413. 


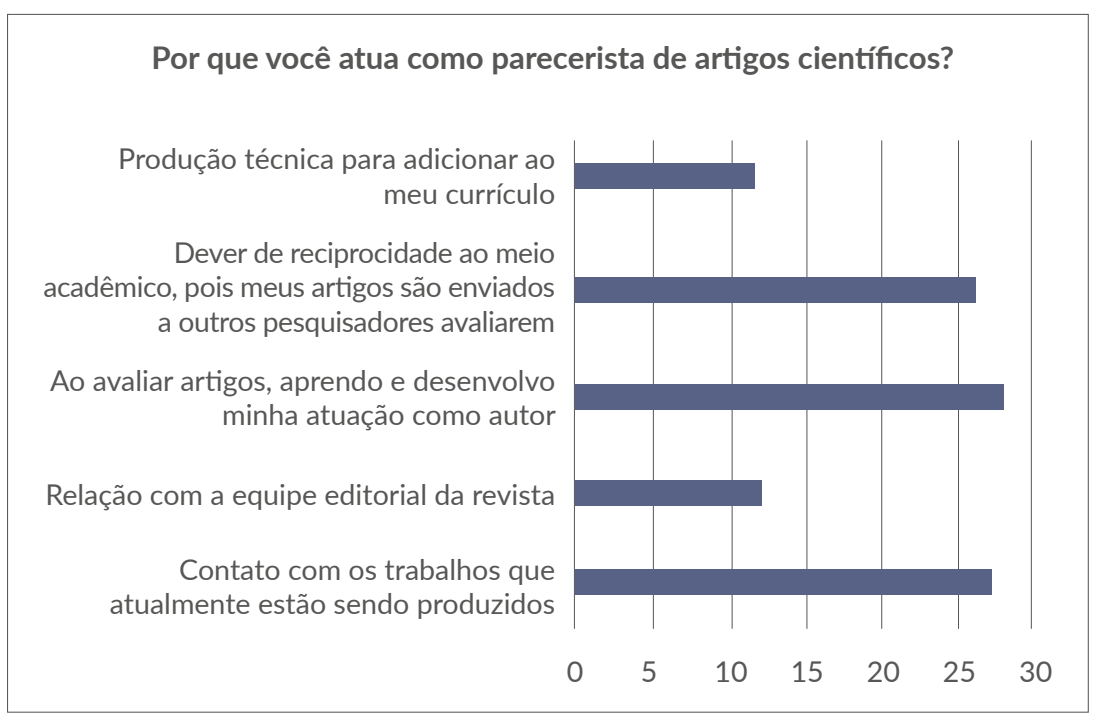

Com relação ao prazo de 15 dias que normalmente é indicado para finalização das avaliações, $82 \%$ dos pareceristas consideraram razoável para a tarefa. Conforme indicado nos questionários, em regra, o processo de avaliação de um artigo demora entre 2 a 4 horas. ${ }^{9}$ Em média, os revisores da RBDPP atuam nessa função em 2 a 4 revistas científicas, mas há casos de pesquisadores que afirmaram vinculação com dez ou mais periódicos. Assim, apontaram que emitem, em média, 4 a 6 pareceres por ano, com pesquisadores que informaram produzir mais de 10 ou 20 pareceres por ano.

Para reconhecimento da atuação dos pareceristas, a parceria com o sistema Publons foi produtiva e bem recebida, pois 39 avaliadores realizaram cadastro e reconheceram 54 pareceres. Questionados sobre sugestões para maior valorização dos revisores, três apontaram a recomendação de remuneração pela produção. Certamente, medida primordial é a valorização de tal atuação pela própria Capes em seus mecanismos de avaliação. Um ponto diferencial da RBDPP foi muito

9 Expondo, por meio de pesquisa empírica, que a média é 5 horas: WARE, Mark. Peer review survey 2015, p. 34. 
bem considerado pelos avaliadores: o envio da decisão editorial e dos demais pareceres, após a finalização do processo editorial; pois $94 \%$ dos revisores afirmaram que leram tal feedback e que isso ajudará no aprimoramento de futuras avaliações.

Considerando a visão dos pareceristas, o sistema de controle por pares em periódicos científicos é fundamental e positivo, sendo que nenhum o considerou uma intrusão abusiva no pensamento do autor:

\section{Qual a importância do controle por pares para a} produção do conhecimento científico?

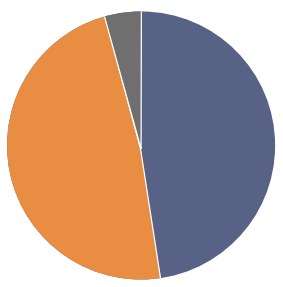

Sem controle por pares não há produção de conhecimento científico confiável (21)

É importante para aprimorar os artigos (21)

Embora problemático, não existe opção melhor (2)

É uma intrusão abusiva no pensamento do autor (0)

Por fim, com relação ao sistema de controle por pares e o anonimato entre os envolvidos no processo editorial, as visões foram distintas. $\mathrm{Na}$ visão de autores, por uma pequena margem, a maioria considera que a adoção de um modelo aberto, em que revisores tenham conhecimento da identidade dos escritores dos artigos, seria prejudicial à imparcialidade da avaliação, mas quantidade razoável considera tal medida positiva para a publicidade do processo. ${ }^{10}$ Já na visão de pareceristas, a maioria

10 Dos 28 pesquisadores que responderam o questionário, 14 apontaram que a identificação de autoria fragiliza a imparcialidade da avaliação, 13 afirmaram que isso seria positivo para a publicidade do sistema e 1 ficou em dúvida, sem opinar. 
(64\%) mostrou-se tendente a aceitar e incentivar um sistema aberto, com a divulgação dos nomes dos avaliadores aos autores dos artigos. Tal cenário indica a possibilidade de adoção de sistemática "mista", em que o controle por pares inicialmente se realizaria de modo duplo-cego (sem identificação de autores e avaliadores), mas, após a finalização do processo editorial, seria realizada a divulgação das identificações dos pareceristas, especialmente dos artigos aprovados e publicados (o que permitiria, inclusive, a publicação dos pareceres juntamente ao artigo analisado). ${ }^{11}$

\section{REFERÊNCIAS}

BARATA, Rita C. B. Dez coisas que você deveria saber sobre o Qualis. Revista Brasileira de Pós-graduação, Brasília, v. 13, n. 30, p. 13-40, jan./abr. 2016. https:// doi.org/10.21713/2358-2332.2016.v13.947

CAPPARELLI, Bruna; GIACOMOLLI, Nereu J. Editorial: a avaliação do impact Factor na publicação científica de Direito Processual Penal. Revista Brasileira de Direito Processual Penal, Porto Alegre, vol. 3, n. 3, p. 789-806, set./dez. 2017. https://doi.org/10.22197/rbdpp.v3i3.108

GALÍCIA, Caíque R. Editorial: O pesquisador e a pesquisa em ciências criminais na contemporaneidade. Revista Brasileira de Direito Processual Penal, Porto Alegre, vol. 3, n. 3, p. 769-787, set./dez. 2017. https://doi.org/10.22197/rbdpp.v3i3.100

SHIGAKI, Helena; PATRUS, Roberto. Revisão por pares e produtivismo acadêmico sob a ótica de avaliadores de artigos de periódicos em Administração. Revista Brasileira de Pós-graduação, Brasília, v.13, n. 31, p. 399-428, mai./ago. 2016. https:// doi.org/10.21713/2358-2332.2016.v13.960

SILVEIRA, Vladmir O.; SANCHES, Samyra H. F. N. Periódicos na área do Direito: o desafio da superação da cultura dos livros. Revista da Faculdade de Direito da UERJ, Rio de Janeiro, n. 30, p. 157-172, dez. 2016. http://dx.doi.org/10.12957/ rfd.2016.17961

${ }^{11}$ Uma opção seria publicar os pareceres junto aos artigos aprovados e questionar aos respectivos avaliadores se autorizam a divulgação de sua identificação, apontando a autoria daqueles que autorizarem. Assim, seria possível reconhecer e certificar a produção daqueles que desejarem e, ao mesmo tempo, manter o sigilo para quem assim preferir. 
VASCONCELLOS, Vinicius G. Editorial: a função do periódico científico e do editor para a produção do conhecimento no Direito e nas ciências criminais. Revista Brasileira de Direito Processual Penal, Porto Alegre, vol. 3, n. 1, p. 9-17, jan./abr. 2017. https://doi.org/10.22197/rbdpp.v3i1.34

VASCONCELLOS, Vinicius G. Editorial: Controle por pares e a função do revisor - premissas e orientações para uma avaliação consistente. Revista Brasileira de Direito Processual Penal, Porto alegre, vol. 3, n. 2, p. 437-458, mai./ago. 2017. https://doi.org/10.22197/rbdpp.v3i2.70

VASCONCELLOS, Vinicius G. Editorial: As rodadas de correções e a carta-resposta do autor à aprovação condicionada - sobre o controle e o aprimoramento dos artigos no processo editorial científico. Revista Brasileira de Direito Processual Penal, Porto Alegre, vol. 3, n. 3, p. 757-768, set./dez. 2017. https://doi.org/10.22197/ rbdpp.v3i3.101

WARE, Mark. Peer review: benefits, perceptions and alternatives. London: Publishing Research Consortium, 2009. Disponível em: <http://publishingresearchconsortium. com/index.php/prc-documents/prc-research-projects/35-prc-summary-4-warefinal-1/file>. Acesso em: 23 dez. 2017.

WARE, Mark. Peer review survey 2015. London: Publishing Research Consortium, 2016. Disponível em: <http://publishingresearchconsortium.com/index.php/ prc-documents/prc-research-projects/57-prc-peer-review-survey-2015/file>. Acesso em: 23 dez. 2017. 


\section{Informações adicionais e declarações do autor (integridade científica)}

Agradecimentos (acknowledgement): Agradeço a Daniel Leonhardt pela leitura crítica do texto, com indicação de correções e sugestões.

Declaração de conflito de interesses (conflict of interest declaration): o autor confirma que não há conflitos de interesse na realização das pesquisas expostas e na redação deste editorial.

Declaração de autoria (declaration of authorship): todas e somente as pessoas que atendem os requisitos de autoria deste editorial estão listadas como autores.

Declaração de ineditismo e originalidade (declaration of originality): o autor assegura que o texto aqui publicado não foi divulgado anteriormente em outro meio e que futura republicação somente se realizará com a indicação expressa da referência desta publicação original; também atesta que não há plágio de terceiros ou autoplágio.

\section{COMO CITAR ESTE EDITORIAL:}

VASCONCELLOS, Vinicius G. Editorial: Presente e futuro do controle por pares e da editoração científica no Direito - perspectivas a partir dos dados da RBDPP em 2017 e das visões de seus autores e avaliadores.

Revista Brasileira de Direito Processual Penal, Porto Alegre, vol. 4, n. 1, p. 1123, jan./abr. 2018. https://doi.org/10.22197/rbdpp.v4i1.132

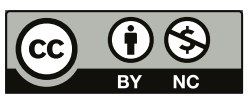

Esta obra está licenciada com uma Licença Creative Commons Atribuição-NãoComercial 4.0 Internacional. 